\title{
Impaired Memory Retention and Decreased Long-Term Potentiation in Integrin-Associated Protein-Deficient Mice
} Hui P. Chang, ${ }^{1}$ Frederik P. Lindberg, ${ }^{2}$ Hai L. Wang, ${ }^{1}$ A.M. Huang, ${ }^{3}$ and Eminy H.Y. Lee ${ }^{3,4}$

${ }^{1}$ Graduate Institute of Life Sciences

National Defense Medical Center

Taipei 106, Taiwan, Republic of China

${ }^{2}$ Departments of Infectious Diseases and Molecular Microbiology

Washington University School of Medicine

St. Louis, Missouri 63110 USA

${ }^{3}$ Institute of Biomedical Sciences

Academia Sinica

Taipei 115 Taiwan, Republic of China

\section{Abstract}

Previously, we have demonstrated that integrin-associated protein (IAP) mRNA level is approximately fourfold higher in rats showing good retention performance $(600$ sec) than rats showing poor retention performance $(<80 \mathrm{sec})$ in an inhibitory avoidance learning paradigm. In the present study, we have used the gene-targeted IAP-deficient mice to further investigate the role of IAP involved in memory formation and hippocampal long-term potentiation (LTP) in vivo. Results revealed that there was a significant impairment in memory retention and a significant reduction in the magnitude of LTP in IAP-deficient mice when compared with the wild-type and heterozygote mice, whereas the wild-type and heterozygote animals did not show marked differences on these measures. Furthermore, the impairment in retention performance of IAP-deficient mice was not due to different sensitivities of these animals to the electric shock. When we examined locomotor activity and rotarod treadmill performance, no differences were observed among these three groups of animals either. Western blot analysis confirmed the lack of

${ }^{4}$ Corresponding author.
IAP protein in IAP-deficient mice, whereas IAP expression was similar in both the wild-type and heterozygote controls. These results together demonstrate that IAP plays an important role in the process of memory formation and synaptic plasticity in mice.

\section{Introduction}

Vertebrate memory formation requires de novo gene expression and protein synthesis as mRNA and protein synthesis inhibitors are known to impair long-term memory formation (Davis and Squire 1984). Long-term memories are also believed to be stored by modification of pre-existing synapses or formation of new synaptic contacts (Weiler et al. 1995). Using a PCR differential display method, previously we have found that hippocampal integrin-associated protein (IAP) mRNA levels are fourfold higher in rats showing good retention performance than in poor memory controls or untrained animals in a one-way inhibitory avoidance learning task (Huang et al. 1998). Furthermore, IAP antisense oligonucleotide treatment significantly impaired retention performance and inhibited long-term potentiation (LTP), a synaptic model for long-term memory (Bliss and Collingridge 1993) in rats (Huang et al. 1998). These results suggest that IAP mRNA expression is necessary for memory formation and synaptic plasticity in rats.

Integrins are heterodimeric cell surface recep-

LEARNING \& MEMORY 6:448-457 @ 1999 by Cold Spring Harbor Laboratory Press ISSN1072-0502/99 \$5.00

$$
\begin{array}{lllllllllllllll}
L & E & A & R & N & I & N & G & \underset{448}{\boldsymbol{Q}} & M & E & M & O & R & Y
\end{array}
$$


tors that mediate regulated cell-cell interactions and adhesive interactions between cells and the extracellular matrix (ECM) proteins (Juliano and Haskill 1993; Clark and Brugge 1995). Recent evidence has shown that integrins are also involved in various central nervous system functions (for review, see Jones 1996). For example, integrins are known to be involved in anatomical organization and neurite growth during development (Reichardt and Tomaselli 1991; Defreitas et al. 1995). More related to the present study, integrin and integrinlike proteins are involved in neuroplasticity because the integrin antagonist GRGDSP and the GRGDSP analog peptides have been shown to inhibit LTP in rats (Staubli et al. 1990, 1998).

The IAP is a $50-\mathrm{kD}$ ubiquitously expressed membrane glycoprotein that is associated with integrin (Brown et al. 1990) and regulates the function of $\alpha_{v} \beta_{3}$ class of integrins in placenta and platelets (Lindberg et al. 1993, 1996b). It also acts as a receptor for the cell-binding domain of the thrombospondin (TSP) family of ECM proteins (Schwartz et al. 1993; Gao et al. 1996a,b). In a very recent study, IAP has been demonstrated to have its selective binding partner on the cell membrane of cerebellar neurons (Jiang et al. 1999). Immunological studies have shown that IAP can also act independent of $\beta_{3}$ integrins in T-cell costimulation (Reinhold et al. 1997). These results suggest that IAP may have independent physiological functions.

In the present study, we aimed to further investigate the role of IAP involved in memory processing and LTP. If IAP does play an important role in memory formation and synaptic plasticity, it is expected that both retention performance and LTP are impaired in animals deficient in IAP. To test this hypothesis, we have used IAP-deficient mice and have adopted both the in vivo LTP model and the inhibitory avoidance learning paradigm, the paradigm originally used to demonstrate the IAP gene (Huang et al. 1998). Flow cytometry of red blood cells was used to verify the genotype of all animals and Western blot analysis was used to verify the lack of the IAP protein in IAP knockout mice. Our results demonstrate that IAP plays an essential role in the process of memory formation and synaptic plasticity in rats and mice.

\section{Materials and Methods}

\section{ANIMALS}

The IAP-null allele was back crossed from $\mathrm{IAP}^{+/-} 129 \mathrm{sv} / \mathrm{eg}$ mice (Lindberg et al. 1996b) into
Balb/cJ for seven to nine generations. These mice were then interbred and male $\mathrm{IAP}^{+/+}, \mathrm{IAP}^{+/-}$, and $\mathrm{IAP}^{-/-}$offspring were used for the present study at age 2-3 months (weight, 20-25 grams). Their genotypes were confirmed by flow cytometry of red blood cells. Briefly, the tail blood was collected into PBS/5 mm EDTA, washed, and red blood cells corresponding to $1 \mu \mathrm{l}$ of blood stained for $30 \mathrm{~min}$ at $4^{\circ} \mathrm{C}$ with $1 \mu \mathrm{g}$ of miap301 (IAP monoclonal antibody; Lindberg et al. 1996b) in $30 \mu \mathrm{l}$ of complete medium. Cells were washed and stained under the same conditions with $1 \mu \mathrm{l}$ of goat-anti-rat IgG-FITC (Sigma Co.). At least 10,000 cells were analyzed after a final wash. Gene dosage allows easy distinction among $\mathrm{IAP}^{+/+}, \mathrm{IAP}^{+/-}$, and $\mathrm{IAP}^{-/-}$genotypes. In the analysis of $>300$ samples with this method, it has $100 \%$ concordance with the PCR/Southern blot analysis (Lindberg et al. 1996b) and this method was more likely to be technically successful. All experimental animals were typed at least twice. In selective animals, brain tissues were also subjected to Western blot analysis for verification of IAP protein expression. Besides, all experiments were conducted in compliance with the "Guidelines for Animal Care" provided by The National Institutes of Health (NIH) and approved by the Animal Committee of the Institute of Biomedical Sciences, Academia Sinica (Taiwan, Republic of China).

\section{INHIBITORY AVOIDANCE LEARNING}

The one-way inhibitory avoidance learning task was used to measure retention performance in mice. The apparatus consists of a trough-shaped alley divided by a sliding door into an illuminated safe compartment and a dark compartment. A shock generator with facilities to vary current is connected to the floor of the dark compartment. The behavioral task included the training and testing procedures and was conducted between 10:00 a.m. and 5:00 p.m. Before experimentation, mice were kept in a dim room for $1 \mathrm{hr}$ to adjust to the environment. For the training phase, the mouse was placed at the far end of the illuminated compartment facing away from the door. As the mouse turned around, the door was open. When the mouse entered the dark compartment, the door was closed and a 1.2-mA/1-sec footshock was given. The animal was then removed from the alley and returned to its home cage. Three hours later, the retention test was given. The animal was again

$$
\begin{array}{lllllllllllllll} 
& E & A & R & N & I & N & G & \begin{array}{r}
\boldsymbol{Q} \\
449
\end{array} & M & E & M & O & R & Y
\end{array}
$$


placed into the illuminated compartment and the latency to step into the dark compartment was recorded as the measure of retention performance. The ceiling score was assigned as $600 \mathrm{sec}$. The observer was blinded as to the genotype of the mice.

\section{LOCOMOTOR ACTIVITY ASSAY}

After the memory retention test, mice were placed into a locomotor activity chamber for 20 min. The chamber is $\sim 16$ inch square with $16 \times 16$ horizontal by vertical infrared sensors connected to two digiscan activity monitors (Coulbourn Instrument, PA). The sensors were used to localize the animals floor position and quantify locomotor activity level. Locomotor activity was measured as the total number of beam breaks in an $x-y$ plane recorded every 10 msec.

\section{ROTAROD TREADMILL PERFORMANCE}

After the locomotor activity test, mice were subjected to the rotarod treadmill endurance measure. Basically, it consists of a set of a $25-\mathrm{cm}$ diameter drums, enabling five mice to be placed on the treadmill simultaneously. The rotor has an angular speed that can be varied by a simple belt gear. They are driven by heavy-duty induction geared motors. For this experiment, the speed was set at six turns/min and the mice were placed on the center grid of the rotarod. The timer was stopped automatically when the animal fell off the grid onto the plate below and the total time the mouse stayed on the grid was recorded as the endurance measure.

\section{SHOCK SENSITIVITY TEST}

At the end of all behavioral experiments (and before LTP recording), the same mice were placed into the dark compartment of the alley used for individual measurement of memory retention. Each animal was given different intensities of electric shock at $0,0.4,0.8,1.2$, and $1.6 \mathrm{~mA}$ DC current for $1 \mathrm{sec}$ at each intensity in sequence. The interval between two adjacent shock intensities was 10 sec. Their responses to the shocks were recorded by the experimenter. In general, their responses can be divided into the following categories: flinch, locomotion, vocalization, and jump. If an animal expressed more than one behavioral category during the shock, these responses were all recorded and counted.

\section{ELECTROPHYSIOLOGY}

For in vivo LTP recording, mice were anesthetized with intraperitoneal urethane (1.2 gram $/ \mathrm{kg}$ ) and placed on a stereotaxic instrument. Throughout the surgery and experiments, core body temperature was monitored and maintained at $35 \pm 1^{\circ} \mathrm{C}$ through a heating pad with a thermoprobe placed in the rectum of the mouse. The skull was exposed and electrodes implanted through burr holes in the skull. The stimulating electrodes were platinum concentric bipolar electrodes with a tip diameter of $25 \mu \mathrm{m}$ and were positioned unilaterally to the dorsomedial perforant path at stereotaxic coordinates of $0.5 \mathrm{~mm}$ anterior to lambda, $2.5 \mathrm{~mm}$ lateral to the midline, and $1.5-2.0 \mathrm{~mm}$ ventral to the brain surface. Recording electrodes were prepared from single-barrel glass micropipettes (1.2-mm outer diam. $\times$ 0.6-mm inner diam.), pulled on a Narishige vertical puller, and filled with $3 \mathrm{~m} \mathrm{NaCl}$. Resistance ranged from 1 to $3 \mathrm{M} \Omega$. The recording electrodes were implanted ipsilaterally into the dentate gyrus, $2.0 \mathrm{~mm}$ posterior to the bregma, $1.0 \mathrm{~mm}$ lateral to the midline, and 1.5-2.0 $\mathrm{mm}$ ventral to the brain surface. Once both the recording and stimulating electrodes were positioned, 5\% agar dissolved in $0.9 \% \mathrm{NaCl}$ was applied over the exposed skull to prevent surface drying and reduce movement artifacts. To avoid noise interference with LTP recording, one end of an electrical wiring was connected to the metal hood on top of the recording instruments and the other end to the wall. The other wiring from the outlet of the oscillator was connected to the recording electrode and to the head skin of the mouse serving as a ground reference. Stimulation consisted of 50usec duration monophasic constant current pulses delivered once every $10 \mathrm{~min}$. Stimulus intensities ranged from 100 to $500 \mu \mathrm{A}$ and produced averaged pEPSP (population excitatory postsynaptic potential) amplitudes of $4-7 \mathrm{mV}$. Once determined, stimulus current remained constant throughout the experiment. To induce LTP, one set of stimuli in 10-min periods was delivered after a 30-min baseline recording in mice. This set of stimuli contained four trains, eight pulses per train at $400 \mathrm{~Hz}$, delivered at a rate of one train/sec for $20 \mathrm{msec}$. The pulse width used was $400 \mu \mathrm{sec}$. The popula-

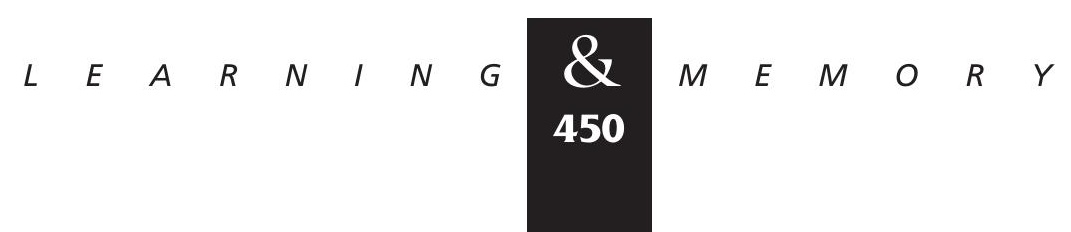


tion spike amplitude, slope, and amplitude of the pEPSP were recorded once every $10 \mathrm{~min}$.

\section{WESTERN BLOT ANALYSIS}

Animals of each IAP genotype were sacrificed and whole brain tissues were homogenized in $4 \mathrm{ml}$ of hypotonic buffer containing 20 mM HEPES ( $\mathrm{pH}$ 7.5), $5 \mathrm{~mm} \mathrm{KCl}, 1 \mathrm{~mm} \mathrm{MgCl}_{2}, 1 \mathrm{~mm}$ EDTA, $10 \mu \mathrm{g} / \mathrm{ml}$ leupeptin, $10 \mu \mathrm{g} / \mathrm{ml}$ aprotinin, and $5 \mathrm{~mm}$ DFP. Icecold acetone in a volume of $36 \mathrm{ml}$ was added. The homogenate was centrifuged at $15,000 \mathrm{~g}$ for $10 \mathrm{~min}$ and the precipitate was collected. The pellet was resuspended in $2 \mathrm{ml}$ of hypotonic buffer by brief sonication, with CHAPS added to a final concentration of $10 \mathrm{~mm}$, followed by incubation on ice for 10 min. After centrifugation at $15,000 \mathrm{~g}$ for $10 \mathrm{~min}$, the pellet was collected and again resuspended in $2 \mathrm{ml}$ of hypotonic buffer. SDS was added to make a final concentration of $1 \%(\mathrm{wt} / \mathrm{vol})$ and the solution cleared by centrifugation at $15,000 \mathrm{~g}$ for $5 \mathrm{~min}$. Fifty microliters of this preparation was loaded on a $10 \%$ SDS-polyacrylamide gel. After gel analysis, proteins were transferred to polyvinylidine difluoride (PVDF) membrane by semidry transfer method in an electrophoretic transfer kit. The PVDF membrane was blocked in blocking buffer (Tris-buffered saline, $0.1 \%$ Tween-20/2\% BSA) for $1 \mathrm{hr}$ at room temperature, then incubated for $2 \mathrm{hr}$ at room temperature in primary antibody, miap301 (1 $\mu \mathrm{g} /$ $\mathrm{ml}$ in blocking buffer), followed by three washes of 5 min each in washing buffer (Tris-buffered saline, $0.1 \%$ Tween-20). Incubation in secondary antibody (1:1000 peroxidase conjugated goat-anti-rat in blocking buffer) was for $1 \mathrm{hr}$ at room temperature. After three washes of $10 \mathrm{~min}$ each in washing buffer, bound antibody was detected using chemoluminescent substrate (ECL, Amersham) and X-ray film.

\section{STATISTICAL ANALYSIS}

Because the distribution of the retention scores was uneven and was truncated at 600, nonparametric Mann-Whitney one-tailed $U$ test was used to analyze the data for retention performance. The $U$ value was then transferred to the $Z$ value. Other behavioral comparisons and electrophysiological results were evaluated with one-way analysis of variance (ANOVA) followed by Dunnett's $t$ test for comparisons between $\mathrm{IAP}^{+/+}$and $\mathrm{IAP}^{-/-}$ groups as well as between $\mathrm{IAP}^{+/-}$and $\mathrm{IAP}^{-/-}$ groups.

\section{Results}

RETENTION PERFORMANCE OF IAP ${ }^{+/+}, \mathrm{IAP}^{+/-}$, AND $\mathrm{IAP}^{-/-} \mathrm{MICE}$

The wild-type (IAP $\left.{ }^{+/+}, n=13\right)$, heterozygote $\left(\mathrm{IAP}^{+/-}, n=11\right)$, and IAP knockout mice $\left(\mathrm{IAP}^{-/-}\right.$, $n=17$ ) were trained in the inhibitory avoidance learning apparatus and memory retention was measured $3 \mathrm{hr}$ later. Results indicated that retention performance was significantly impaired in IAP knockout mice either compared with the wild-type ( $U=69, Z=1.74, P<0.05$ ) or compared with the heterozygote $(U=48, Z=2.14, P<0.05)$ controls. There was no marked difference in retention performance between the wild-type and the heterozygote groups $(U=65, Z=0.38, P>0.05)$. One would suspect that retention performance may be affected by factors other than memory consolidation, such as motor activity and balance. However, the present results indicated that there was no significant difference among these animals in locomotor activity $(F(2,38)=0.50, P>0.05)$ and rotarod treadmill endurance $(F(2,38)=0.55, \quad P>0.05)$ measures. Further analyses indicated that the IAP knockout mice were not different from the wildtype and heterozygote controls when compared in locomotor activity (tD $=0.97, \quad P>0.05$ and $\mathrm{tD}=0.64, P>0.05$, respectively) (Fig. $1 \mathrm{~B}$ ) and rotarod treadmill performance $(\mathrm{tD}=0.10, P>0.05$ and $t D=1.0, P>0.05$, respectively) (Fig. 1C) separately. Also, there was no obvious difference among these three groups of animals in their sensitivities or responses to the electric shock (Table 1).

LTP RECORDING OF IAP ${ }^{+/+}, \mathrm{IAP}^{+/-}$, AND $\mathrm{IAP}^{-/-} \mathrm{MICE}$

Next, the wild-type (IAP $\left.{ }^{+/+}, n=5\right)$, heterozygote $\left(\mathrm{IAP}^{+/-}, n=5\right)$, and IAP knockout $\left(\mathrm{IAP}^{-/-}\right.$, $n=6)$ mice were subjected to electrophysiological recording of LTP in vivo. Results revealed that basic synaptic transmission in the hippocampus was the same in these three groups of mice (0-30 min, one-way ANOVA, $F(2,13)=1.62, P>0.05)$; however, there was an overall significant difference in the slope of pEPSP among these groups of animals upon tetanic stimulation $(40-210 \mathrm{~min}$, $F(2,13)=3.89, P<0.05)$. Further analyses indicated that the IAP knockout mice showed a significant reduction in the slope of pEPSP when compared to the wild-type $(69 \%$ reduction, $\mathrm{tD}=2.82$, $P<0.05)$ and the heterozygote $(62 \%$ reduction,

$$
\begin{array}{lllllllllllllll}
L & E & A & R & N & I & N & G & \boldsymbol{\bigotimes} \\
\mathbf{4 5 1} & M & E & M & O & R & Y
\end{array}
$$



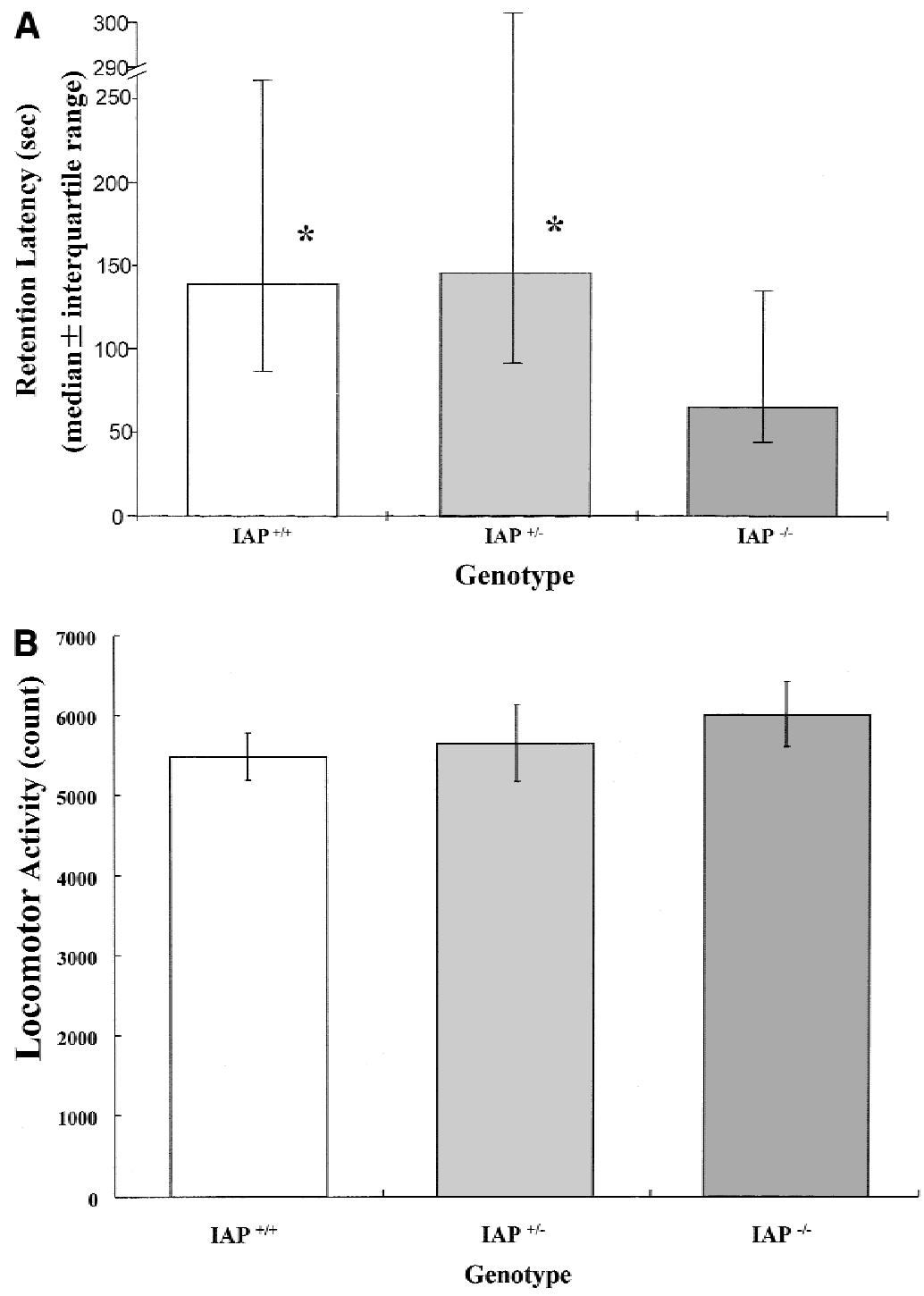

Figure 1: $(A)$ Retention performance of homozygote $\left(\mathrm{IAP}^{+/+}, n=13\right)$, heterozygote $\left(\mathrm{IAP}^{+/-}, n=11\right)$, and IAP knockout $\left(\mathrm{IAP}^{-/-}, n=17\right)$ mice in an inhibitory avoidance learning task. Data are expressed as median \pm interquartile range. The comparisons between $\mathrm{IAP}^{+/+}$and $\mathrm{IAP}^{-1-}$ groups, as well as between the $\mathrm{IAP}^{+/-}$and $\mathrm{IAP}^{-/-}$groups, were significant (both $P<0.05$, Mann-Whitney one-tailed $U$ test. $(B)$ Locomotor activity level of the same mice measured in a digiscan activity monitor for $20 \mathrm{~min}(P>0.05)$. (C) Endurance time of the same animals measured in a rotarod treadmill $(P>0.05)$. Data are expressed as mean \pm S.E.M. in $B$ and $C$.

C

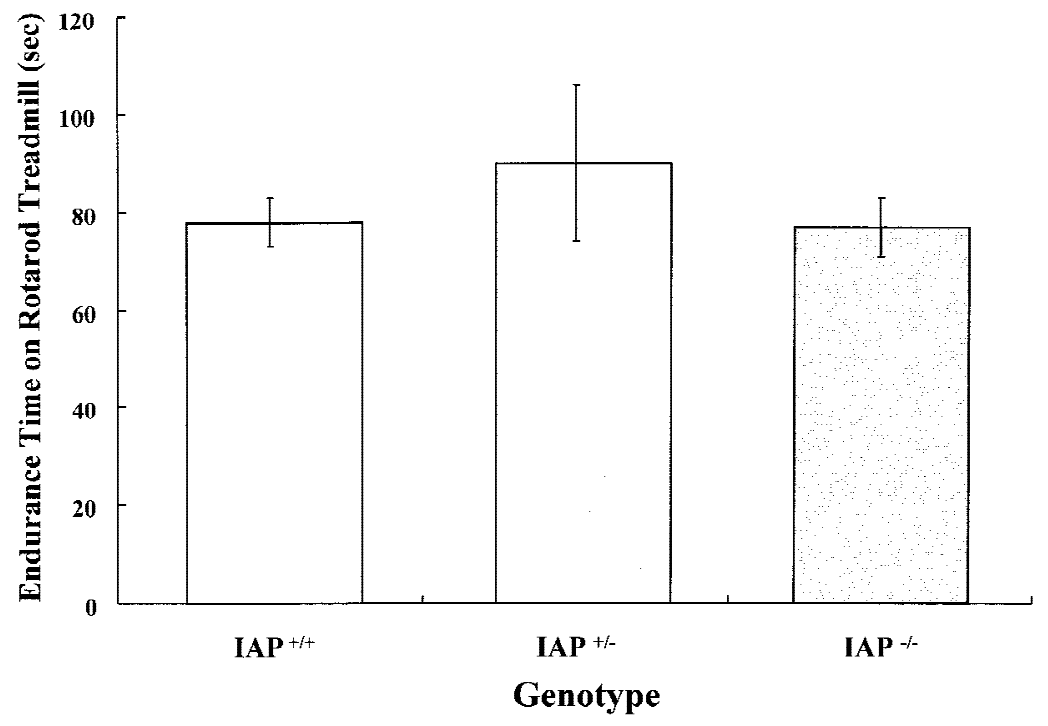

$$
\begin{array}{lllllllllllllll}
\hline & E & A & R & N & I & N & G & \begin{array}{l}
\boldsymbol{Q} \\
\mathbf{4 5 2}
\end{array} & M & E & M & O & R & Y
\end{array}
$$




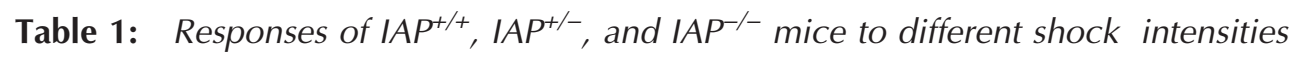

\begin{tabular}{|c|c|c|c|c|c|c|}
\hline \multirow[b]{2}{*}{ Genotype } & \multirow[b]{2}{*}{ No. ${ }^{a}$} & \multicolumn{5}{|c|}{ Shock intensity $(\mathrm{mA})^{\mathrm{b}}$} \\
\hline & & 0 & 0.4 & 0.8 & 1.2 & 1.6 \\
\hline $\mathrm{APP}^{+/+}$ & 13 & - & $\underset{(17 \%}{F} \quad \underset{(63 \%)}{L} \quad V$ & $L, J, V$ & $\mathrm{~J}, \mathrm{~V}$ & $\mathrm{~J}, \mathrm{~V}$ \\
\hline $\mathrm{IAP}^{+/-}$ & 11 & - & 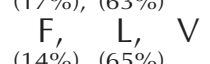 & $L, J, V$ & $J, V$ & $J, V$ \\
\hline $\mathrm{IAP}^{-/-}$ & 17 & - & 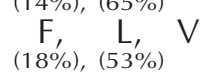 & $L, J, V$ & $\mathrm{~J}, \mathrm{~V}$ & $J, V$ \\
\hline
\end{tabular}

${ }^{a}$ Number of animals.

b(F) Flinch; (L) locomotion; (V) vocalization; (J) jump. Values parentheses indicate the percentage of animals showing that specific response category. Response categories without percentage expression indicate all animals in that group show that behavioral response. There is no marked difference in any behavioral response observed among IAP $\mathrm{P}^{+/+}, \mathrm{IAP}^{+/-}, \mathrm{and}^{\mathrm{IAP}} \mathrm{I}^{-/-}$ mice at any shock intensity examined.
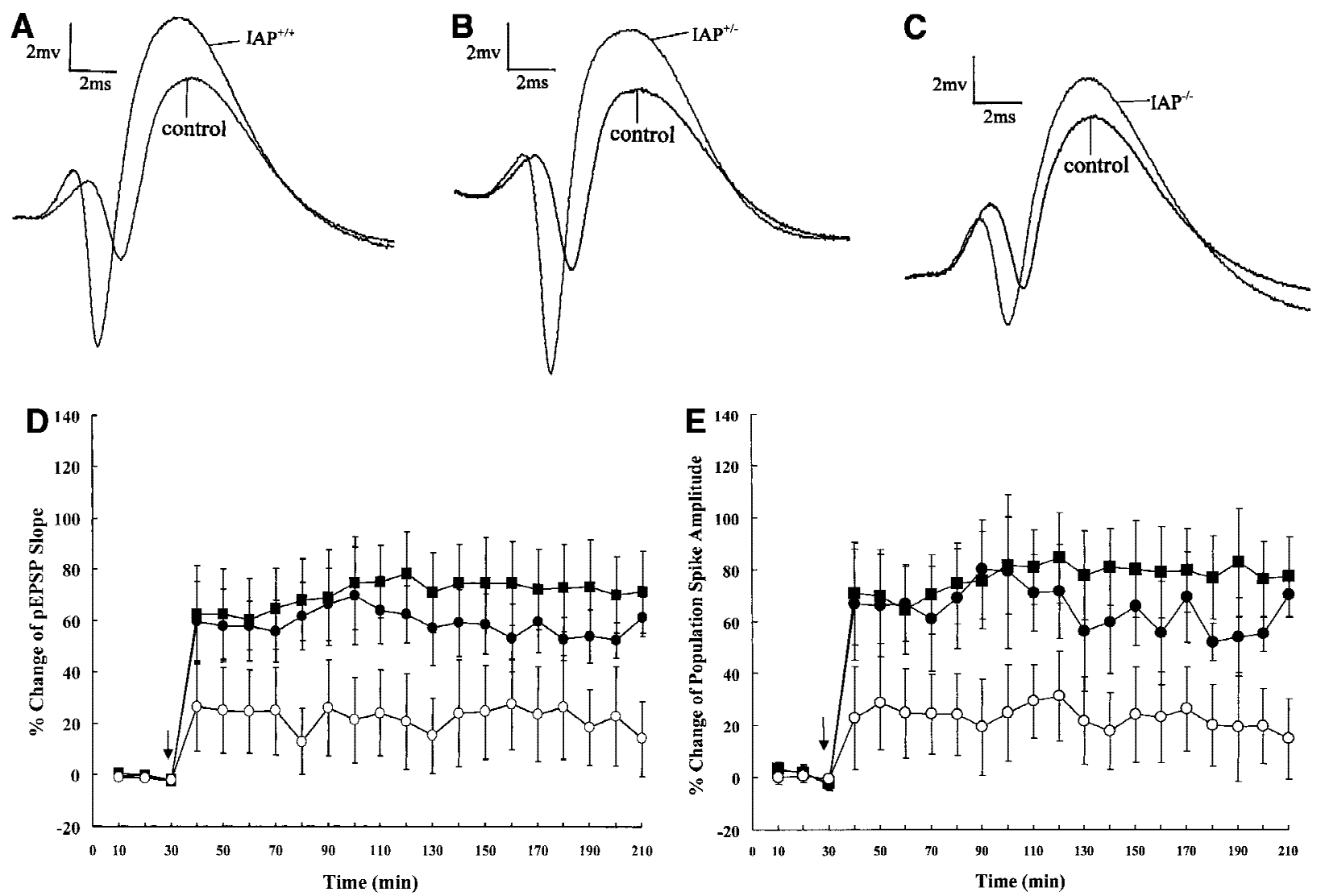

Figure 2: Representative illustrations showing a single response in population spike of $(A) \mathrm{IAP}^{+/+},(B) \mathrm{IAP}^{+/-}$, and $(C)$ $\mathrm{IAP}^{-/-}$mice. $(D)$ Tetanic stimulation-induced LTP in IAP ${ }^{+/+}(n=5), \mathrm{IAP}^{+/-}(n=5)$, and IAP $\mathrm{IA}^{-/}(n=6)$ mice. A significant reduction in the slope of pEPSP in IAP ${ }^{-/-}$mice $(\bigcirc)$ was observed when compared to the IAP $\mathrm{IP}^{+/+}(\mathbf{\square})$ and IAP $\mathrm{I}^{+/-}(\mathbf{O})$ groups (both $P<0.05$, one-way ANOVA followed by Dunnett's $t$-test). There was no marked difference between IAP ${ }^{+/+}$and $\mathrm{IAP}^{+/-}$groups $(P>0.05)$. (E) As in $D$, a significant reduction in the amplitude of population spike was also observed in $\mathrm{IAP}^{-/-}$mice when compared with $\mathrm{IAP}^{+/+}$and $\mathrm{IAP}^{+/-}$mice (both $P<0.05$ ). Again, no marked difference was observed between $\mathrm{IAP}^{+/+}$and $\mathrm{IAP}^{+/-}$groups $(P>0.05)$ (symbols the same as in $\left.D\right)$. Data are expressed as mean \pm S.E.M.. Arrow indicates tetanic stimulation.

$$
\begin{array}{lllllllllllllll}
L & E & A & R & N & I & N & G & \underset{\mathbf{4 5 3}}{\mathbf{Q}} & M & E & M & O & R & Y
\end{array}
$$


$\mathrm{tD}=2.36, P<0.05)$ controls (Fig. 2D). Although no marked difference was found between the wildtype and the heterozygote groups $(\mathrm{tD}=0.63$, $P>0.05)$. Similarly, there was also a marked difference in the magnitude of population spike (40-210 $\min , F(2,13)=4.17, P<0.05)$. Further analyses revealed that it is also because of the differences between the IAP knockout and wild-type groups (68\% reduction, $\mathrm{tD}=2.72, P<0.05$ ) as well as between the IAP knockout and heterozygote groups (64\% reduction, $\mathrm{tD}=2.12, P<0.05$ ) (Fig. 2E). Again, no marked difference was found between the wild-type and the heterozygote groups (tD $=0.57, P>0.05)$.

\section{WESTERN BLOT OF IAP}

At the end of all behavioral and electrophysiological experiments, selective animals from each group were subjected to Western blot analyses of IAP protein expression. As shown in Figure 3, results revealed that no IAP labeling was found in IAP knockout mice, whereas IAP staining was abundant and the expression level was similar in both the wild-type and heterozygote animals.

\section{Discussion}

The present results demonstrate that there was a significant impairment in retention performance and a significant reduction in the magnitude of LTP in IAP knockout mice when compared with the wild-type and the heterozygote controls, whereas the wild-type and heterozygote mice did not show marked difference on these measures. These differ-

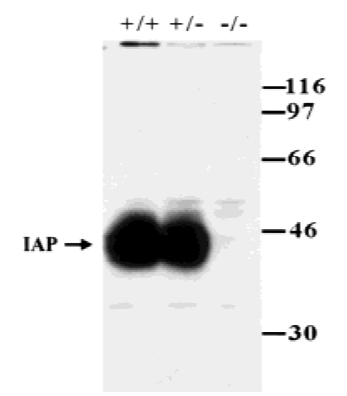

Figure 3: Representative gel pattern showing the results of Western blotting of IAP expression in the whole brain of $\mathrm{IAP}^{+/+}, \mathrm{IAP}^{+/-}$, and $\mathrm{IAP}^{-/-}$mice. IAP monoclonal antibody (miap301; Lindberg et al. 1996b) was used. IAP protein was absent in IAP ${ }^{-/-}$mice and IAP expression was similar in both $\mathrm{AP}^{+/+}$and $\mathrm{IAP}^{+/-}$mice. ences did not appear to be secondary to generalized disturbance because sensitivity to the electric shock, balance, and motor activity were not markedly different in the experimental animals. Western blot analyses confirmed the lack of IAP protein in IAP knockout mice, but IAP expression was abundant in both the wild-type and heterozygote animals. These results together demonstrate the importance of IAP involved in memory processing and synaptic plasticity in mice.

Both LTP and vertebrate memory are complex processes. In both cases, there are underlying changes in synaptic function and likely also reorganization of cell-cell contacts (Weiler et al. 1995; Mullany and Lynch 1997). Application of neural cell adhesion molecule (NCAM) antibodies was shown to inhibit the induction of hippocampal LTP in rats (Ronn et al. 1995), whereas memory consolidation induces an increase in NCAM polysialylated cells in the same region (Fox et al. 1995; Murphy et al. 1996), suggesting that cell adhesion molecules may play an important role in both synaptic plasticity and memory processing. This suggestion is also supported by a recent finding that the Drosophila mutant Valado, which is deficient in the integrin- $\alpha$-subunit, also shows impaired short-term memory (Grotewiel et al. 1998). In some regards, IAP can also be viewed as a kind of cell adhesion molecule. For example, IAP has an extracellular domain belonging to the immunoglobulin superfamily (Lindberg et al. 1993), suggesting that it may function independently as a cell-cell or cell-matrix receptor (Yoshihara et al. 1991). IAP is also a receptor for the thrombospondin matrix protein family, several of which induce neurite outgrowth (Arber and Caroni 1995; Gao et al. 1996a,b). Interestingly, thrombosponding- 4 , the most abundant thrombospondin in the adult central nervous system, is highly expressed in synapserich regions, especially in CA1, CA3, and dentate gyrus neurons (Arber and Caroni 1995), which are the sites of maximal IAP expression upon learning (Huang et al. 1998). Therefore, like NCAM and integrin, IAP may also be viewed as a cell adhesion molecule whose expression is essential for memory consolidation and synaptic plasticity.

Then, how might IAP act to facilitate memory formation? Does it act in association with integrin or function independently, or both? At present, this is unclear. However, the difficulty in clarifying the relationship between integrin and IAP lies in the fact that the integrin antagonist GRGDSP and its analog peptide have an inhibitory effect on LTP

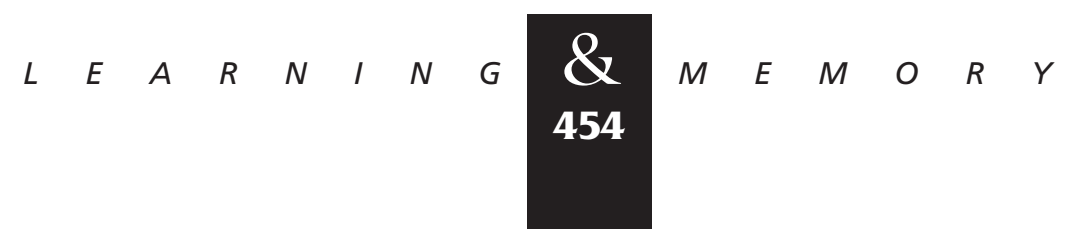


per se (Staubli et al. 1990, 1998); therefore, it may also impair memory performance in rats, and thus, making the integrin-IAP interaction study difficult. Future studies using functional antibodies against IAP will be helpful in elucidating its mechanism of action. On the other hand, IAP may act through binding to the ECM protein and subsequent activation of the signal transduction pathway. In platelet, the IAP agonist $4 \mathrm{~N} 1 \mathrm{~K}$ (kRFYVVMWKk) was shown to activate the function of $\alpha_{\mathrm{IIb}} \beta_{3}$ integrin, resulting in an assembly of a signaling complex containing integrin, IAP, and various kinases, including the focal adhesion kinase (Chung et al. 1997). We do not know whether the same signaling pathway also occurs in the hippocampus and explains the reason for memory processing. However, focal adhesion kinase is actually enriched in the cerebral cortex and the hippocampus (Burgaya et al. 1995). Its high levels have been found in the growth cones and perikarya in developing neurons as well as in the adult hippocampus (Burgaya et al. 1995). This implicates its importance in neuronal plasticity and perhaps, behavioral plasticity. Furthermore, in a very recent study, Jiang et al. (1999) have shown that IAP is a predominant binding partner of another adhesive membrane protein P84 (also known as SHPS-1, B1T, and SIRP) in the mammalian brain. Application of anti-IAP antibody was shown to inhibit cell attachment to P84 in cerebellar neuronal cultures. Whether IAP also acts in associated with P84 to facilitate synaptic transmission and memory processing requires further investigation. The exact mechanism and the signaling pathway underlying the action of IAP in memory processing also remains to be elucidated.

In the present study, although the IAP knockout mice showed a significant impairment in retention performance and hippocampal LTP, both measures were not completely inhibited. This is probably because the signal transduction upon IAP binding to the ECM protein was inhibited in these animals. However, the signal transduction along axonal flow may remain normal; therefore, neurotransmitter release in the hippocampus, such as glutamate release, is not affected, which then maintains the normal physiological functions of these neurons. In addition, significant differences exist among different mouse strains in memory performance and the Balb/cJ mice may not be the most sensitive strain for inhibitory avoidance learning (Lipp and Wolfer 1998). Furthermore, other molecules with similar characteristics to IAP may also participate in synaptic plasticity, such as integrin
(Staubli et al. 1990, 1998). On the other hand, results of Western blotting experiments are consistent with that of Lindberg et al. (1996b) using Southern blotting to confirm the IAP mutant. This is the first report demonstrating IAP expression in the mammalian brain. Further experiments using immunohistochemistry to examine IAP distribution in different brain regions and the subcellular distribution of IAP are under investigation. In the present study, the mice used were back crossed for seven to nine generations and no difference was seen between the wild-type and heterozygote groups, making it very unlikely that the observed behavioral difference is attributable to an unlinked locus. The possibility remains that the effect is due to a highly IAP-linked locus. However, the similar memory impairment and LTP reduction seen in mice treated with IAP antisense oligonucleotide (Huang et al. 1998) and in IAP knockout mice argues against this possibility. Moreover, our histological results showed that the hippocampal structure was the same in these three groups of animals (unpubl. observations), suggesting that the observed differences in the present study were not due to preexisting structural or developmental differences between IAP knockout and control mice.

In the present study, the IAP knockout mice were only subjected to the one-way inhibitory avoidance learning test. Although the hippocampus is known to involve in a variety of learning and memory tasks, including the inhibitory avoidance learning (Lee et al. 1993; Bevilaqua et al. 1997), this paradigm may not be one of the central hippocampus-dependent tasks. Other tasks, such as the Morris water maze learning, will be helpful in elucidating the specific role that IAP plays in learning and memory.

In summary, in the present study we have used the IAP knockout mice to further investigate the role of IAP in long-term memory formation and hippocampal LTP in vivo. Results demonstrate that both retention performance and the magnitude of LTP were significantly impaired in IAP knockout mice. This difference is not due to a difference in the animal's sensitivity to electric shock or a difference in motor activity level. Western blot results confirm the lack of IAP protein in IAP knockout mice. Furthermore, similar behavioral and electrophysiological results obtained in IAP knockout mice and rats treated with IAP antisense oligonucleotide as well as similar hippocampal structure observed between IAP knockout and control mice argue against the possibility of a preexisting differ-

$$
\begin{array}{lllllllllllllll} 
& E & A & R & N & I & N & G & \begin{array}{r}
\boldsymbol{Q} \\
455
\end{array} & M & E & M & O & R & Y
\end{array}
$$




\section{Chang et al.}

ence in hippocampal organization during development in IAP knockout mice. These results demonstrate that IAP plays an important role in both memory formation and hippocampal synaptic plasticity in rats and mice.

\section{Acknowledgments}

We thank Y.L. Ma for his technical assistance and Alex Zheleznyak for conducting the Western blot experiments. This work was supported by a grant (NSC88-2312-B001-013) from the National Science Council of Taiwan, Republic of China, and NIH grant GM-57573-01.

The publication costs of this article were defrayed in part by payment of page charges. This article must therefore be hereby marked "advertisement" in accordance with 18 USC section 1734 solely to indicate this fact.

\section{References}

Arber, S. and P. Caroni. 1995. Thrombospondin-4, an extracellular matrix protein expressed in the developing and adult nervous system promotes neurite outgrowth. J. Cell Biol. 131: 1083-1094.

Bevilaqua, L., P. Ardenghi, N. Schroder, E. Bromberg, P.K. Schmitz, E. Schaeffer, J. Quevedo, M. Bianchin, R. Walz, J.H. Medina, and I. Izquierdo. 1997. Drugs acting upon the cyclic adenosine monophosphate/protein kinase A signalling pathway modulate memory consolidation when given late after training into rat hippocampus but not amygdala. Behav. Pharmacol. 8: 331-338.

Bliss, T.V. and G.L. Collingridge. 1993. A synaptic model of memory: Long-term potentiation in the hippocampus. Nature 361: 31-39.

Brown, E., L. Hooper, T. Ho, and H. Gresham.1990. Integrin-associated protein: A 50-kD plasma membrane antigen physically and functionally associated with integrins. J. Cell Biol. 111: 2785-2794.

Burgaya, F., A. Menegon, M. Menegoz, F. Valtorta, and J.A. Girault. 1995. Focal adhesion kinase in rat central nervous system. Eur. J. Neurosci. 7: 1810-1821.

Chung, J., A.G. Gao, and W.A. Frazier. 1997. Thrombospondin acts via integrin-associated protein to activate the platelet integrin $\alpha_{1 \mathrm{lb}} \beta_{3}$. J. Biol. Chem. 272: 14740-14746.

Clark, E.A. and J.S. Brugge. 1995. Integrins and signal transduction pathways: The road taken. Science 268: 233-239.

Davis, H.P. and L.R. Squire. 1984. Protein synthesis and memory: A review. Psychol. Bull. 96: 518-559.

Defreitas, M.F., C.K. Yoshida, W.A. Frazier, D.L. Mendrick, R.M. Kypta, and L.F. Reichardt. 1995. Identification of integrin alpha 3 beta 1 as a neuronal thrombospondin receptor mediating neurite outgrowth. Neuron 15: 333-343.
Fox, G.B., A.W. O'Connell, K.J. Murphy, and C.M. Regan. 1995. Memory consolidation induces a transient and time-dependent increase in the frequency of neural cell adhesion molecule polysialylated cells in the adult rat hippocampus. J. Neurochem. 65: 2796-2799.

Gao, A.G., F.P. Lindberg, M.B. Finn, S.D. Blystone, E.J. Brown, and W.A. Frazier. 1996a. Integrin-associated protein is a receptor for the C-terminal domain of thrombospondin. J. Biol. Chem. 271: 21-24.

Gao, A.G., F.P. Lindberg, J.M. Dimitry, E.J. Brown, and W.A. Frazier. 1996b. Thrombospondin modulates alpha $v$ beta 3 function through integrin-associated protein. J. Cell Biol. 135: 533-544.

Grotewiel, M.S., C.D. Beck, K.H. Wu, X.R. Zhu, and R.L. Davis. 1998. Integrin-mediated short-term memory in Drosophila. Nature 391: 455-460.

Huang, A.M., H.L. Wang, Y.P. Tang, and E.H.Y. Lee. 1998. The expression of integrin-associated protein gene associated with memory formation in rats. J. Neurosci. 18: 4305-4313.

Jiang, P., C.F. Lagenaur, and V. Narayanan. 1999. Integrin-associated protein is a ligand for the P84 neural adhesion molecule. J. Biol. Chem. 274: 559-562.

Jones, L.S. 1996. Integrins: Possible functions in the adult CNS. Trends Neurosci. 19: 68-72.

Juliano, R.L. and S. Haskill. 1993. Signal transduction from the extracellular matrix. J. Cell Biol. 120: 577-585.

Lee, E.H.Y., C.P. Lee, H.I. Wang, and W.R. Lin. 1993. Hippocampal CRF, NE, and NMDA system interactions in memory processing in the rat. Synapse 14: 144-153.

Lindberg, F.P., H.D. Gresham, E. Schwarz, and E.J. Brown. 1993. Molecular cloning of integrin-associated protein: An immunoglobulin family member with multiple membrane-spanning domains implicated in alpha $v$ beta 3-dependent ligand binding. J. Cell Biol. 123: 485-496.

Lindberg, F.P., H.D. Gresham, M.I. Reinhold, and E.J. Brown. 1996a. Integrin-associated protein immunoglobulin domain is necessary for efficient vitronectin bead binding. J. Cell Biol. 134: 1313-1322.

Lindberg, F.P., D.C. Bullard, T.E. Caver, H.D. Gresham, A.L. Beaudet, and E.J. Brown. 1996b. Decreased resistance to bacterial infection and granulocyte defects in IAP-deficient mice. Science 274: 795-798.

Lipp, H.P. and D.P. Wolfer. 1998. Genetically modified mice and cognition. Curr. Opin. Neurobiol. 8: 272-280.

Mullany, P. and M.A. Lynch. 1997. Changes in protein synthesis and synthesis of the synaptic vesicle protein, synaptophysin, in entorhinal cortex following induction of long-term potentiation in dentate gyrus: An age-related study in the rat. Neuropharmacology 36: 973-980.

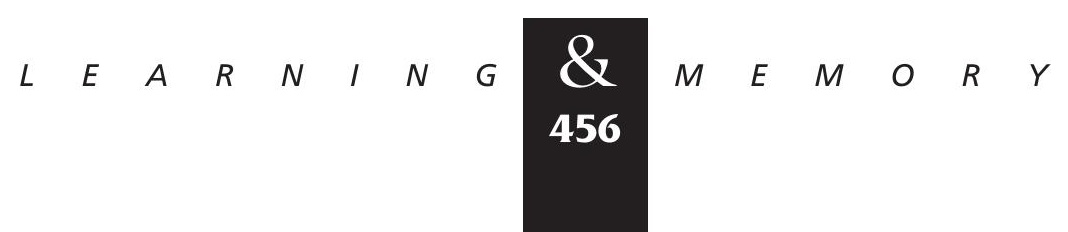


Murphy, K.J., A.W. O'Connell, and C.M. Regan. 1996.

Repetitive and transient increases in hippocampal neural cell adhesion molecule polysialylation state following multitrial spatial training. J. Neurochem. 67: 1268-1274.

Reichardt, L.F. and K.J. Tomaselli. 1991. Extracellular matrix molecules and their receptors: Functions in neural development. Annu. Rev. Neurosci. 14: 531-570.

Reinhold, M.I., F.P. Lindberg, G.J. Kersh, P.M. Allen, and E.J. Brown. 1997. Costimulation of T cell activation by integrin-associated protein (CD47) is an adhesion-dependent, CD28-independent signaling pathway. J. Exp. Med.

185: $1-11$.

Ronn, L.C., E. Bock, D. Linnemann, and H. Jahnsen. 1995. NCAM-antibodies modulate induction of long-term potentiation in rat hippocampal CA1. Brain Res. 677: 145-151.

Schwartz, M.A., E.J. Brown, and B. Fazeli. 1993. A 50-kDa integrin-associated protein is required for integrin-regulated calcium entry in endothelial cells. J. Biol. Chem.

268: 19931-19934.

Staubli, U., P. Vanderklish, and G. Lynch. 1990. An inhibitor of integrin receptors blocks long-term potentiation. Behav. Neural Biol. 53: 1-5.

Staubli, U., D. Chun, and G. Lynch. 1998. Time-dependent reversal of long-term potentiation by an integrin antagonist. J. Neurosci. 18: 3460-3469.

Weiler, I.J., N. Hawrylak, and W.T. Greenough. 1995. Morphogenesis in memory formation: Synaptic and cellular mechanisms. Behav. Brain Res. 66: 1-6.

Yoshihara, Y., S. Oka, J. Ikeda, and K. Mori. 1991. Immunoglobulin superfamily molecules in the nervous system. Neurosci. Res. 10: 83-105.

Received June 14, 1999; accepted in revised form August 20, 1999. 


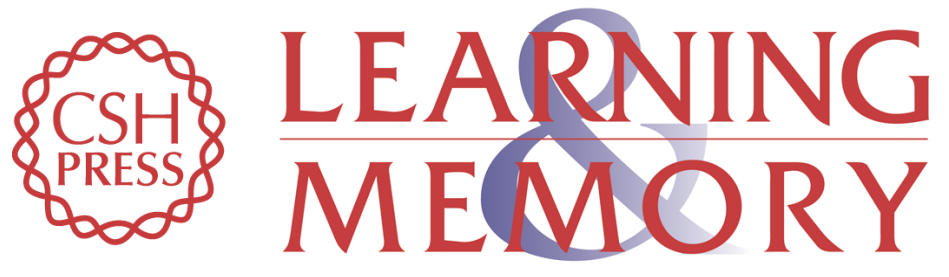

\section{Impaired Memory Retention and Decreased Long-Term Potentiation in Integrin-Associated Protein-Deficient Mice}

Hui P. Chang, Frederik P. Lindberg, Hai L. Wang, et al.

Learn. Mem. 1999, 6:

Access the most recent version at doi:10.1101//m.6.5.448

References This article cites 32 articles, 15 of which can be accessed free at: http://learnmem.cshlp.org/content/6/5/448.full.html\#ref-list-1

License

Email Alerting Receive free email alerts when new articles cite this article - sign up in the box at the Service top right corner of the article or click here. 